\title{
Designation of an urban monitoring network based on Local Climate Zone mapping and temperature pattern modelling
}

Running page head: Designation of an urban monitoring network

\author{
Lelovics E, Unger J, Gál T \\ Department of Climatology and Landscape Ecology, University of Szeged, Szeged, Hungary \\ lelovics.eniko@gmail.com, unger@geo.u-szeged.hu
}

\begin{abstract}
The recently developed Local Climate Zones (LCZ) classification system was not originally designed for mapping, but to classify and standardize urban heat island observation sites. Nevertheless, if the aim is to characterize the areas with different thermal reactions within a wider study area, the mapping seems to be a useful application of the system.

Our objectives are: (i) to develop GIS methods to calculate different parameters describing the LCZs for any part of the study area, (ii) to identify and delineate the LCZ types occuring in the study area using the calculated parameters, (iii) to select representative sites of an urban monitoring network using the mapped LCZs and modelled mean annual temperature surplus pattern.

The input data were: 3D building, road and Corine Land Cover databases, aerial photographs, topographic map and RapidEye satellite image. The basic area of calculation was the building block with the area belonging to (polygon). These polygons classified with the same or similar parameter values were aggregated to evolve the appropriate size zones. As a result, six built LCZ types were distinguished in the studied urban area.

An estimation of the temperature pattern was obtained by an empirical model. In order to designate the 24 stations of the network the sites were selected inside the delineated LCZ areas taking also the modelled pattern into account. The exact places on the lamp posts were determined by field surveys. The bias between the temperature pattern interpolated from the modelled values of the 24 stations and the originally estimated pattern was found to be satisfactory.
\end{abstract}

Key words: Urban climate, Monitoring network, LCZs, GIS methods, Modelled temperature pattern, Szeged, Hungary

\section{Introduction}

Owing to the anthropogenic activity, a local climate develops in the built-up areas. Nowadays about half of the human population is affected by the artificial urban environments. This makes studies dealing with the urban impact on climate particularly important. By definition the urban climate is a local climate that is modified by interactions between built-up area and regional climate (WMO 1983). This urban climate is different from the pre-urban (natural) one and is a result of accelerated urbanization: construction of buildings, roads, etc., as well as of the emission of heat, moisture and pollution related to human activities. Among the parameters of the urban atmosphere the near-surface (screen-height: 1.5-2 metres above ground level) air temperature shows the most obvious modification compared to the rural area (Oke 1987).

This urban warming is commonly referred to as the urban heat island (UHI) and its magnitude is the UHI intensity. Traditionally, this intensity is interpreted as the difference between values measured in the city centre (urban) and a nearby undeveloped (rural) site $\left(\Delta \mathrm{T}_{\mathrm{u}-\mathrm{r}}\right)$. Nevertheless, in the heat island literature the term "urban" has no single, objective meaning as the areas around the measuring sites could be very different depending on the investigated cities (e.g. park, college ground, street canyon, housing estate, etc.). Similarly, the surroundings of the "rural" sites varied in different studies, it may be e.g. airport, farmland, field, or even a less built suburb.

That is, on the one hand, for landscape classification or description of the site surroundings the simple "urban"/"rural" ( $\mathrm{u} / \mathrm{r})$ is not really appropriate because of the abundant variety of the landscapes according to their surface properties which are reflected in the development of nearsurface micro and local climates (Stewart 2007, 2011). This makes (almost) impossible to compare the results obtained in different parts of the world.

On the other hand, if the investigation is directed on the detailed monitoring of the representative temperature distribution within the city, this is a difficult task because of the 
complexity and variety of the urban terrain (Oke, 2004). The site locations of an intra-urban station network and thus the question about its appropriate configuration raises an essential problem. This problem is related to the relationship between the intra-urban built and land cover types and the locations of the network sites. Two situations arise:

Situation (1): In the case of an already existing network (e.g. Schroeder et al. 2010, Siu \& Hart 2013) it may be required to characterize the relatively wider environment around the measuring sites, namely what type of urban area surrounds a given station and whether it can be clearly determined. In other words, how representative is the location of a station regarding a specific, clearly defined urban environment type, that is, whether the data measured at this location are typical for the thermal reactions of a given urban area?

Situation (2): In the case of a planned station network (e.g. Unger et al. 2011) the most important questions are what surface types can be distinguished in the given urban area, how precisely they can be delimited, how many they are, and whether their extension is large enough to install a station somewhere in the middle of the area (representing the thermal conditions of this type) while of course taking care to minimize the microclimatic effects of the immediate surroundings (e.g. sunlit walls, AC heat emission). For the accurate positioning some temperature information (earlier measurements, modelling) can be an additional help.

To address the questions raised above, Stewart \& Oke (2012) developed the "local climate zone" (LCZ) classification system, which describes the exposure and land cover characteristics of a screen-height temperature sensor, that is the LCZs intend to reflect the thermal reactions of a wider environment. It can be applied relative easily in any urban or rural environment. It is based on the earlier classifications of Auer (1978), Ellefsen (1991), Oke (2004) and Stewart \& Oke (2009), as well as a world-wide survey of heat island measurement sites and their local settings (Stewart 2011). The elements of this system are presented shortly in Section 2.

The LCZ classification system was not designed specifically for mapping - it was designed to standardize the classification of urban heat island observation sites, whether urban or rural, fixed or mobile. Nevertheless, if the aim is to establish a new urban observation network, spatial mapping of the urban terrain is a justifiable use of the system to determine areas that are relatively homogeneous in surface properties and human activities, and to identify sites that are representative of those areas. The studies in Hamburg, Germany (Bechtel \& Daneke 2012) and Xuzhou, China (Gamba et al. 2012) were among the first steps for automated extraction of LCZ areas in urban environment using applied GIS and remote sensing methods.

The present study is connected to an EU-founded project (URBAN-PATH 2013). As a part of this project urban monitoring systems are under development. When completed they will provide online information in a form of maps on temperature, humidity and human comfort conditions within Szeged and Novi Sad (Serbia) (Lazic et al. 2006). The temperature and relative humidity stations (24 items in Szeged and 28 in Novi Sad) of the monitoring system will be located on lamp posts according the above mentioned Situation (2).

The objective of this paper is three-fold: (i) to develop GIS methods in order to calculate geometric, surface cover and radiative parameters describing the LCZs for any part of the study area using different databases which are available or created for this purpose, (ii) to identify and delineate the LCZ types which occur in the study area using the calculated surface parameters by the developed methods and (iii) to select representative sites of the urban monitoring network using the mapped LCZs and the modelled mean temperature surplus pattern.

\section{Brief description of the LCZ classification system}

The necessity and ideas of the development of the "local climate zone" classification system and its structure are presented and discussed in detail in Stewart \& Oke (2012). Therefore here we highlight only the key features of the system.

The primary purpose of the system is to facilitate the characterization of the local environment around a temperature measuring site, in terms of its ability to influence the local 
thermal climate. To this end, the number of types (zones) is not too large and separation is based on objective, measurable parameters. LCZs are defined as "regions of uniform surface cover, structure, material, and human activity that span hundreds of meters to several kilometres in horizontal scale. Each LCZ has a characteristic screen-height temperature regime that is most apparent over dry surfaces, on calm, clear nights, and in areas of simple relief" (Stewart \& Oke 2012). Each zone is necessarily "local" in spatial scale because an upwind fetch of typically 200-500 $\mathrm{m}$ is required for air at screen-height to become fully adjusted to the underlying, relatively homogeneous surface.

The main characters of the types are reflected in their names (Table 1).

The LCZ types can be distinguished by the typical value ranges of measurable physical properties (parameters) (Table 2). These parameters largely characterize the surface geometry and cover, but there are also those that reflect the thermal, radiative and anthropogenic energy features of the surface. Stewart \& Oke (2012) give typical values for the properties of each zone.

The interpretation of the above mentioned parameters are as follows: (1) sky view factor (SVF) is the proportion of the sky dome that is ,seen” by a surface, either from a particular point of that surface or integrated over its entire area (Errel et al. 2011), (2) aspect ratio (H/W) is the ratio between the average height of adjacent vertical elements and the average width of the space (Errel et al. 2011), (3) building surface fraction (BSF) is the ratio between the horizontal area of buildings on a given area and the total area, (4) impervious surface fraction (ISF) is the ratio between the horizontal area of impervious surfaces on a given area and the total area, (5) pervious surface fraction (PSF) is the ratio between the horizontal area of pervious surfaces on a given area and the total area, (6) height of roughness elements (HRE) is the average height of the roughness elements on a given area, (7) terrain roughness class (TRC) is the classification of the different urban and natural landscapes into 8 class by the surface roughness increment (Davenport et al. 2000), (8) surface admittance (SAD) is a measure of the ability of a surface to accept or release heat (Oke 1987), (9) surface albedo (SA) is the average ratio between the reflected and incident short wave radiation on a given area, (10) anthropogenic heat output $(\mathrm{AH})$ is the heat generated by human activities on a given area.

In the context of the new LCZ classification system, the intra-urban UHI intensity is not an "urban-rural" temperature difference $\left(\Delta \mathrm{T}_{\mathrm{u}-\mathrm{r}}\right)$, but an LCZ temperature difference $\left(\Delta \mathrm{T}_{\mathrm{LCZ}} \mathrm{X}-\mathrm{Y}\right)$ (Stewart et al. 2013). This difference can take various forms depending on the pairing of two LCZ types. In this way, the application of the LCZ system gives opportunity to objectively compare the thermal reactions of different areas within a city (intra-urban) and between cities (inter-urban).

\section{Study area and earlier temperature measurements}

Szeged is located in the south-eastern part of Hungary $\left(46^{\circ} \mathrm{N}, 20^{\circ} \mathrm{E}\right)$ at $79 \mathrm{~m}$ above sea level on a flat terrain with a population of 160,000 within an urbanized area of about $40 \mathrm{~km}^{2}$ (Figs. 1a and $1 \mathrm{~b}$ ). The area is in Köppen's climatic region $\mathrm{Cfb}$ (temperate warm climate with a rather uniform annual distribution of precipitation). The annual mean temperature is $10.4^{\circ} \mathrm{C}$ and the mean annual amount of precipitation is $497 \mathrm{~mm}$ (Unger et al. 2001). The study area covers a rectangle of $10 \mathrm{~km}$ $\times 8 \mathrm{~km}\left(80 \mathrm{~km}^{2}\right)$ in and around Szeged (Fig. 1c).

To validate our results, temperature values originated from our earlier mobile measure campaign were used. These measurements were taken by cars at the same time after sunset on fixed return routes during a one-year period (April 2002 - March 2003) by several times in a grid network (e.g. Unger, 2004). For validation four cases were selected, when the weather was clear and calm in the time of the measurement and in the preceding days too, thus during these nights the weather conditions promoted the surface influence on the thermal conditions in the near-surface air layer.

\section{GIS methods developed for LCZ mapping}

\subsection{Parameter calculations for lot area polygons}


Using our method we can determine seven properties from the ten geometric, surface cover and radiative ones listed by Stewart \& Oke (2012) for any given area inside the study area based on the available databases. From the initial parameters for classification we omitted the H/W since this ratio tends to be too theoretical, it can be clearly calculated just in the case of the regular street network. The surface admittance and the anthropogenic heat output are also lacking, since these data were not available in the study area.

During the determination processes of the other seven parameters the basic area of the calculation was the building block and the area belonging to it (lot area polygon). The determination of the building blocks and lot area polygons is based on the 3D building database of Szeged which contains more than 22,000 individual buildings with building height information in ESRI shapefile format (Gál \& Unger 2009). Therefore, the buildings touching each other were merged into blocks and then we divided the study area into polygon-shape areas based on these blocks where each polygon consists of the set of points closer to a central building block than to the other blocks. In the case of larger open areas (areas without buildings, e.g. parks, fields, water) the border of the polygon at the edge of the built-up area is at a distance of $100 \mathrm{~m}$ from the nearest block (Fig. 2).

The calculation processes and the applied databases by parameters were as follows:

- SVF: The input was a SVF database with $5 \mathrm{~m}$ horizontal resolution originated from our earlier studies (Gál et al. 2009, Unger 2009). It was calculated using the 3D building database of Szeged with a vector based method. The building database contains building footprint areas as polygon-type data, and the building heights which were measured with photogrammetric methods as attributes of them. During the SVF calculation all of the buildings were regarded with flat roofs and the effect of the vegetation was neglected. The SVF values are related to the street level so they calculated for the points not covered by buildings and these values are averaged inside the lot polygon areas.

- BSF: The input was also the 3D building database of Szeged which contains the buildings footprints in the study area. BSF is the ratio between the sum of building footprint areas and the lot polygon area.

- PSF: The input was a built-up dataset calculated from RapidEye satellite image (RapidEye 2012) using NDVI index, a 1:25000 topographic map, a road database and the Corine Land Cover (CLC) (Bossard et al. 2000) database. The RapidEye image was atmospherically corrected (resolution of $5.16 \mathrm{~m}$ ) and the Normalized Difference Vegetation Index (NDVI) was calculated using bands 3 and 5 (Tucker 1979) and those points were regarded as covered area where the NDVI was below 0.3. The CLC dataset was used to locate the agricultural areas as these areas have small NDVI (like the covered areas) because the amount of plants on them is negligible after harvest. As a second correction the shape of water bodies were digitized from the topographic map because in several cases the water has NDVI values very similar to the values of some building materials. As a last correction the road database was used to locate the asphalt roads in the area because in the urban canyons these roads are usually under tree cover and because the roads which slice agricultural areas do not appear in CLC dataset.

- ISF: Its value was calculated using this formula: ISF $=1-(\mathrm{BSF}+\mathrm{PSF})$.

- HRE: The input was also the 3D building database of Szeged. For each lot area the building heights weighted with their footprint areas were averaged.

- TRC: For describing the roughness the Davenport roughness classification method was used (Davenport et al. 2000). The principle of the classification process is that the roughness parameter $\left(\mathrm{z}_{0}\right)$ and displacement height $\left(\mathrm{z}_{\mathrm{d}}\right)$ values of the studied area are approximately the same as values previously measured on an area with similar surface cover. This widespread method comprises eight classes of roughness. Each polygon was classified into a roughness class with visual interpretation of aerial photographs, the topographical map and the building database.

- SA: As input the atmospherically corrected reflectance values of the 5 band $(440-510 \mathrm{~nm}$, 520-590 nm, 630-685 nm, 690-730 nm, 760-850 nm). RapidEye satellite image were used. 
Broadband albedo was calculated as an average of reflectance values weighted with the integral of the radiation within the spectral range of a given band (Starks et al. 1991, Tasumi et al. 2008).

The calculation processes, the necessary databases and the outputs are shown in the upper and left hand parts of Fig. 3.

\subsection{LCZ mapping - aggregation and generalization of lot area polygons}

According to literature, in the urban environment the temperature value measured at a height of 1.5-2 $\mathrm{m}$ is influenced by its surroundings with a radius of a few hundred meters as a source area (Oke 2004, Unger 2010). Of course this is only a general approach as the source area depends on the type of "urban" environment. If it is compact urban, the source area may only be tens of metres; if it is open urban, it may be many hundreds of metres. It also depends on weather and stability conditions (Oke 2004).

In line with this and the definition of LCZs, the lot area polygons classified into the same or similar LCZ classes were merged into zones of hundreds of meters to several kilometers. In this case, we meet the minimum condition that the measuring site representing an LCZ is at least 250 meters from the boundaries of the zone, such that the relatively homogeneous surroundings of the sites constitute a source area with a radius of $250 \mathrm{~m}$ or greater.

In order to get LCZ areas with appropriate size, the lot area polygons were aggregated into groups by the following procedure:

First, the polygons were classified separately.

(1) From the obtained surface parameters areal mean or percentage values were calculated to represent the polygons. Seven scores were assigned (Fig. 4) to each LCZ categories by polygons according to its fit into the typical ranges given by Stewart \& Oke (2012) and then they were added. Two of the best fitting LCZ categories were assigned to every polygon (for each polygon the best is $L C Z_{x}$ and the second best is $\left.L C Z_{y}\right)$, if its scores were high enough (>3.0). In the case where the scores were too low to fit to any LCZ categories then the polygon was considered as unclassified.

Second, the lot area polygons were merged according to their LCZ category and their location related to each other.

(2) If a lot area polygon was located inside another polygon then the first LCZ class of the small polygon was set to the same as the other polygon.

(3) If all of the neighbors of a polygon (or maximum except one of them) were in the same LCZ class then the class of the polygon was modified to the same as these neighbors.

(4) If a polygon did not have any neighbor in the same class there were two cases. In one case, if there was a neighbor with same $\mathrm{LCZ}_{\mathrm{x}}$ like the polygon's $\mathrm{LCZ}_{\mathrm{y}}$ or same $\mathrm{LCZ}_{\mathrm{y}}$ like the polygon's $L C Z_{x}$, then $L C Z_{x}$ of the polygon was set to the same like its neighbor. In the other case, if there was a neighbor with $L C Z_{x}$ category similar to the polygon's $\mathrm{LCZ}_{\mathrm{x}}$ category then the $\mathrm{LCZ}_{\mathrm{x}}$ of the polygon was modified to the $\mathrm{LCZ}_{\mathrm{x}}$ of the neighbor. Table 3 presents the similarity of the LCZ categories: cross (+) indicates the similarity of two LCZ categories in the upper row and the left column, respectively (e.g. for the LCZ 2 "compact mid-rise" similar LCZs are LCZ 1 and LCZ 3 because of their density category ("compact") is equal and they are different with only one height categories, and LCZ 5 also similar as it has the same height category ("mid-rise")).

(5) The LCZ categories of the remaining non classified and non aggregated polygons were defined as the most frequent of the classes of their neighbors.

Third, the groups of adjacent polygons with a given LCZ category were investigated according to their spatial extension.

(6) If the area of a group covers at least one circle with a radius of $250 \mathrm{~m}$ then it was regarded as an independent LCZ area.

(7) Polygons of groups which did not satisfy the criterion for the size were merged without considering their properties if they were adjacent. If the obtained group was large enough, the category of the group was set to the most frequent category of its parts; else it was joined to one of the adjoining LCZ areas which have the largest number of contacting lot area polygons with it. 
Finally we obtained several LCZ polygons in ESRI shapefile format, what is suitable for prepare maps or to extract spatial information as well.

\section{Site selection process of the temperature monitoring network}

\subsection{Modelling of the annual mean temperature surplus pattern}

In this study the temperature surplus is defined as the temperature excess of the built-up areas compared to the temperature of non-built areas. In order to get its pattern we applied an empirical model which is based on our earlier work (for the details see Balázs et al. 2009). The aim of this model is to estimate the spatial distribution of the annual mean temperature surplus using just a few input parameters. As independent variables $2 \mathrm{D}$ urban surface cover data and the distance from the city boundary were determined for each element of the $0.5 \mathrm{~km} \times 0.5 \mathrm{~km}$ grid in the study area which means 320 grid cells. The artificially covered surface ratio (streets, pavements, parking lots, roofs, etc.), or the built-up ratio (BR) horizontally characterizes the surface of the settlement. It is actually equal to the previously introduced BSF+ISF (see Section 4.1.) but it is determined in a simpler way (remote sensing) without having detailed local information about the given urban area.

In our case we evaluated the same RapidEye satellite image mentioned in Section 4.1. Based on the previously calculated NDVI values all of the pixels of the image were classified into 3 categories (built-up area, vegetation and water surface). Finally for each cell the BR was calculated as the ratio of the number of the built-up pixels to the total number of grid pixels.

According to the empirical model if a grid cell and the cells around it have a BR of $0 \%$ then its temperature surplus is $0^{\circ} \mathrm{C}$ (this cell is free from urban effect). Naturally, these cells are located out of the urbanized area. On the other hand, a cell with some degree of BR has a temperature excess which depends on the location of the cell within the urban area and on the built-up ratio of the cell itself and its surroundings. The modelled value refers to the grid cell centre (Balázs et al. 2009). The isotherms obtained on the basis of the modelled values depict the mean annual temperature surplus within the study area.

\subsection{Process of determining the monitoring network sites}

While searching for the appropriate (representative) locations, two major criteria were considered. First, homogeneous LCZ areas a few hundred metres (min. $250 \mathrm{~m}$ ) wide should be around the sites, and the number of station sites should be roughly proportional to the areas of the different LCZs. Second, the sites should be located at around the high and low temperature surplus areas, as well as at around the areas of the local maxima and stretches assumed by the modelled pattern. The process and its outputs are shown in the right hand and bottom parts of Fig. 3.

There are also a few other minor criteria which have to be considered after the experience of field surveys at the possible sites. For instance, the selected site should be in a typical place inside an LCZ: e.g. in an "Open low-rise" area the station should not be in a parking area of a shop because the properties of its surface cover differs from the characteristic properties of that LCZ resulting a microclimate different from the local climate of the wider environment. In addition, there are areas (mostly in the city center) where there are no suitable places (lamp post) for a station as the public lamps hang on wire suspensions between the buildings, so these streets should be omitted during the site selection process. For safety reasons the sensors should be installed at a height of $4 \mathrm{~m}$ above the ground on arms fixed on the selected lamp posts. The effect of this height on the measured values is expected to be small as the air in a canyon is generally well mixed (Nakamura \& Oke 1988).

\subsection{Interpolated temperature pattern based on station values - estimation of precision}


The geometrical distribution of the measurement stations affects the obtained temperature surplus pattern. In extreme site distribution cases the temperature pattern could be equivocal (e.g. the highest value could be at different places). In order to estimate the precision of the planned monitoring network in this aspect we applied a simple test. We regarded the modelled annual mean temperature surplus pattern (Section 5.1.) as a reference. Using the modelled temperature values of the 320 grid cells we have interpolated the temperature for the 24 planned station sites. Based on only these interpolated values of the stations we interpolated the spatial distribution of the temperature for the whole study area. As a result, we obtained two temperature patterns, one is the modelled pattern (Section 5.1) and the other is an interpolated one from the modelled values of the stations. Naturally, the second one is less detailed because it was generated from only 24 points, but it is appropriate to estimate that the planned network configuration how precisely approach the main characteristics of the temperature pattern in the study area. The representativeness of the network can be evaluated through the estimation of the expected geometric error. During the site selection process several geometric configuration was tested using this method. The final configuration of the monitoring network is the one when the RMS error (calculated with this method) of the built-up area is minimal, and if there are large deviations they should occur in areas around the city.

\section{Results and discussion}

\subsection{Patterns of surface parameters in Szeged}

In order to illustrate the patterns of the calculated parameters with some examples, Fig. 5 shows the spatial patterns of some parameters in a selected part of the inner urban area. This part is crossed by the river Tisza which can be clearly recognized as a white bent (HRE $=0$ and SVF $=1$ ) extending from NNE to SSW.

In the case of HRE most of the building heights are between 10 and 20 meters and only a few of them (e.g. church, clinical block, educational centre, theatre) are higher than $30 \mathrm{~m}$ in the western side of the Tisza. On its eastern side some block of flats exceed this height.

As regards the street level SVF pattern the most obstructed areas (low SVF values) can be found in the inner courtyards of the buildings while the areas with high SVF appear partly in the large parks and squares.

\subsection{LCZ map and modelled temperature surplus pattern in Szeged}

As the study area covered mostly the urbanized parts of the city we focused on the "built" LCZ types. Due to the peculiarities of the city it was expected prior to parameter calculations that some "built" types do not occur in Szeged. These are the high-rise (LCZs 1 and 4), lightweight lowrise (LCZ 7), and heavy industrialized (LCZ 10) zones. Aggregating the similar lot areas using the methods described in Section 4.2. and supplemented by the authors' local knowledge on the study area, a generalized LCZ map was obtained (Fig. 6). As the map shows, the remaining six "built" types cover the urbanized parts of Szeged (LCZs 2, 3, 5, 6, 8 and 9). Their extensions are different (LCZ $2-0.63 \mathrm{~km}^{2}$, LCZ $3-0.67 \mathrm{~km}^{2}$, LCZ $5-4.35 \mathrm{~km}^{2}$, LCZ $6-19.63 \mathrm{~km}^{2}$, LCZ $8-5.91 \mathrm{~km}^{2}$, LCZ $9-15.32 \mathrm{~km}^{2}$ ). Altogether they cover an urban area of $46.51 \mathrm{~km}^{2}$ in Szeged.

From the grid points of the earlier mobile temperature measurements mentioned in Section 3 we selected visually those ones, which - including their radius area of $250 \mathrm{~m}$ - are located inside the delineated LCZ areas (Fig. 7). The measured temperature values were used to check the relation between the types and their air temperature. From the available database four cases were selected. In these times the weather was suitable to develop local climates. Fig. 8 shows the average air temperature difference of the selected (1-15 circle/types) circle areas from the temperature of the furthermost one from the city (regarding as rural) by cases. As it can be expected, compact type areas are warmer then open ones, as well as mid-rise types are warmer then low-rise types. The air 
temperature of the sparsely built area is almost as low as the rural area characterized with land cover types.

As described in Section 5.1. the isotherms are obtained on the basis of the modelled values depict the annual mean temperature differences within the study area. These differences are related to the values of the cells around the urbanized area whose surroundings and the cell itself have a built-up ratio of $0 \%$.

As Fig. 9. shows the isotherms have a roughly concentric shapes with some extending curvature in line with the certain irregularities in the shape of the urbanized area. The highest values $\left(>3^{\circ} \mathrm{C}\right)$ can be found in the most densely built-up central areas.

\subsection{Determination of the urban monitoring network sites in Szeged}

During the site selection process, 24 station sites were identified in the study area. In LCZ 2 and LCZ 3 there is 1 site, in LCZ 5 and LCZ 9 there are 4 sites, in LCZ 6 there are 10 sites and in LCZ 8 there are 2 sites. Two rural (non built LCZ types - D) station sites were also selected in the western and north-eastern parts of study area (Fig. 10).

The final places of the stations on the lamp posts were determined according to the process described in Sections 5.2. and 5.3. and with the help of field surveys on the representativeness of the lamp posts' microenvironments including the suitability of the columns to install the instruments. The immediate surroundings of six stations representing the six built LCZ types occuring in Szeged are presented in Fig. 11. by aerial photographs. These pictures illustrate the characteristic built-up features of these LCZs and their clearly recognizable differences in building size and density, surface cover, etc.

\subsection{Estimation of precision}

In the interpolated temperature surplus pattern (Fig. 12) the main characteristics of the urban temperature modification are observable. The maximum value is about the same and its location is also identical to the modelled temperature field (Fig. 9).

Based on the difference of the modelled and interpolated temperature patterns (Fig. 13) we can found that the absolute error of the monitoring network is below $0.5^{\circ} \mathrm{C}$ on the $78 \%$ of the whole area. Table 4 shows the frequency of errors in details. The area of this small error is in accordance with the built-up part of the study area. There are few places where high error $\left(<-1.5^{\circ} \mathrm{C}\right)$ occurs, but these areas are in the rural part of the study area. RMSE calculated for the built-up area is 0.354 .

The interpolation works better in the case of grid points in built-up region (Fig. 14). In the inner part of the study area the error of interpolation is between -0.5 and $+0.5^{\circ} \mathrm{C}$. On the edge of the study area it can be seen that interpolated temperature field is not as detailed as the original one, isotherms on the edges are more rounded, thus the local temperature anomalies are not well represented there. Its main cause is that the network is sparser on the edges as its aim is to monitor the built-up region of the city.

\section{Conclusions}

In this study we determined the LCZ types in Szeged which are representative for the urbanized area of the city using seven geometric, surface cover and radiative properties from the ten ones listed by Stewart \& Oke (2012). The values of these properties were calculated by GIS methods developed for this purpose and for the appropriate classification of the selected areas we used also our local knowledge about the districts of Szeged. As a result, six built LCZ types were distinguished and mapped in the studied urban area.

Within the delineated LCZ areas 24 sites were selected in order to designate an urban network for temperature measurements. During the selection of the sites we considered (1) their distance from the border of the LCZ zones which include them, (2) the ability of the geometry of the 
network to reproduce the spatial distribution of mean temperature surplus estimated with an empirical model (3), the representativeness of their microenvironment and (4) their suitability to install the instruments.

As a final remarks it should be mentioned that our LCZ mapping is the first step in the development of urban climate maps (UCMs, see e.g. Ren et al. 2011, Acero et al. 2013) which contain classes based by their climatic factors and accordingly information about the spatial distribution of wind and heat loads in the study area.

\section{Acknowledgements}

The study was supported by the Hungary-Serbia IPA Cross-border Co-operation Programme (HUSRB/1203/122/166 - URBAN-PATH), in the case of the first author by the TÁMOP 4.2.4. A/2-11-1-2012-0001 „National Excellence Program - Elaborating and operating an inland student and researcher personal support system convergence program", which project was subsidized by the European Union and co-financed by the European Social Fund, and in the case of the third author by the Hungarian Scientific Research Fund (OTKA PD-100352) and by the János Bolyai Research Scholarship of the Hungarian Academy of Sciences. Special thanks are due to Dr. Iain Stewart (University of Toronto) for helpful suggestions in the earlier stage of the manuscript.

\section{References}

Acero JA, Arrizabalaga J, Kupski S, Katzschner L (2013) Deriving an Urban Climate Map in coastal areas with complex terrain in the Basque Country (Spain). Urban Climate 4:35-60

Auer AH (1978) Correlation of land use and cover with meteorological anomalies. J Appl Meteorol 17:636643

ASTM (2012) American Society for Testing and Materials Reference Solar Spectral Irradiance: Air Mass 1.5. http://rredc.nrel.gov/solar/spectra/am1.5 (accessed 25 Jan 2013)

Balázs B, Unger J, Gál T, Sümeghy Z, Geiger J, Szegedi S (2009) Simulation of the mean urban heat island using 2D surface parameters: empirical modeling, verification and extension. Meteorol Appl 16: 275-287

Bechtel B, Daneke C (2012) Classification of Local Climate Zones based on Multiple Earth observation data. IEEE J Selected Topics in Appl Earth Obs and Rem Sens 99: 1-5

Bossard M, Feranec J, Otahel J (2000) CORINE land cover technical guide - Addendum 2000. Technical report No 40. European Environment Agency, Copenhagen, Denmark

Davenport AG, Grimmond CSB, Oke TR, Wieringa J (2000) Estimating the roughness of cities and sheltered country. Proc 12th Conf on Applied Climatology, Asheville, NC, p 96-99

Ellefsen R (1990) Mapping and measuring buildings in the canopy boundary layer in ten U.S. cities. Energy Build 15-16:1025-1049

Erell E, Pearlmutter D, Williamson T (2011) Urban microclimate. Designing the spaces between buildings. Earthscan, London-Washington

Gál T, Lindberg F, Unger J (2009) Computing continuous sky view factor using 3D urban raster and vector data bases: comparison and application to urban climate. Theor Appl Climatol 95:111-123

Gál T, Unger J (2009) Detection of ventilation paths using high-resolution roughness parameter mapping in a large urban area. Building Environ 44:198-206

Gamba P, Lisini G, Liu P, Du PJ, Lin H (2012) Urban climate zone detection abd discrimination using object-based analysis of VHR scenes. Proceed of the $4^{\text {th }}$ GEOBIA, Rio de Janeiro, Brazil, 071-074

Lazić L, Savić S, Tomić Ž (2006) Analysis of the temperature characteristics and trends in Novi Sad area (Vojvodina, Serbia). Geographica Pannonica 10:14-21

Nakamura Y, Oke TR (1988) Wind, temperature and stability conditions in an east-west oriented urban canyon. Atmos Environ 22:2691-2700

Oke TR (1987) Boundary Layer Climates. (2nd ed.) Routledge, London-New York

Oke TR (2004) Initial guidance to obtain representative meteorological observation sites. WMO/TD No. 1250, Geneva

RapidEye (2012) Satellite Imagery Product $\quad$ Specifications, $\quad$ Version 4.1. http://www.rapideye.com/upload/RE_Product_Specifications_ENG.pdf

Ren C, Ng E, Katzschner L (2011) Urban climatic map studies: A review. Int J Climatol 31:2213-2233

Siu LW, Hart MA (2013) Quantifying urban heat island intensity in Hong Kong SAR, China. Environ Monit Assess 185:4383-4398 
Schroeder AJ, Basara JB, Illston BG (2010) Challenges associated with classifying urban meteorological stations: The Oklahoma City Micronet example. Open Atmos Sci J 4:88-100

Starks PJ, Norman JM, Blad BL, Walter-Shea EA, Walthall CL (1991) Estimation of shortwave hemispherical reflectance (albedo) from bidirectionally reflected radiance data. Rem Sens Environ 38:123134

Stewart ID (2007) Landscape representation and urban-rural dichotomy in empirical urban heat island literature, 1950-2006. Acta Climatol Chorol Univ Szegediensis 40-41:111-121

Stewart, I D (2011) A systematic review and scientific critique of methodology in modern urban heat island literature. Int J Climatol 31:200-217

Stewart ID, Oke TR (2009) A new classification system for urban climate sites. Bull Am Meteorol Soc 90:922-923

Stewart ID, Oke TR (2012) Local Climate Zones for urban temperature studies. Bull Am Meteorol Soc 93:1879-1900

Stewart ID, Oke TR, Krayenhoff ES (2013) Evaluation of the 'local climate zone' scheme using temperature observations and model simulations. Int J Climatol DOI: 10.1002/joc.3746

Tasumi M, Allen RG, Trezza R (2008) At-surface reflectance and albedo from satellite for operational calculation of land surface energy balance. J Hydrol Engineering 13(2):51-63

Tucker CJ (1979) Red and photographic infrared linear combinations for monitoring vegetation. Rem Sens Environ 8:127-150

Unger J (2004) Intra-urban relationship between surface geometry and urban heat island: review and new approach. Clim Res 27:253-264

Unger J (2006) Modelling of the annual mean maximum urban heat island using 2D and 3D surface parameters. Clim Res 30:215-226

Unger J (2009) Connection between urban heat island and sky view factor approximated by a software tool on a 3D urban database. Int J Environ Pollut 36:59-80

Unger J, Sümeghy Z, Gulyás Á, Bottyán Z, Mucsi L (2001) Land-use and meteorological aspects of the urban heat island. Meteorol Appl 8:189-194

Unger J, Gál T, Rakonczai J, Mucsi L, Szatmári J, Tobak Z, van Leeuwen B, Fiala K (2010) Modeling of the urban heat island pattern based on the relationship between surface and air temperatures. Időjárás (Q $\mathrm{J}$ Hungarian Meteorol Service) 114: 287-302

Unger J, Savic S, Gál T (2011) Modelling of the annual mean urban heat island pattern for planning of representative urban climate station network. Adv in Meteorol 2011: ID 398613, p 9

URBAN-PATH homepage (2013) http://adatok.geo.u-szeged.hu/urbanpath/ (accessed 11 Sep 2013)

WMO (1983) Abridged final report, 8th session. Commission for Climatology and Applications of Meteorology,World Meteorological Organization (WMO No. 600), Geneva

WMO (1996) Climatological Normals (CLINO) for the period 1961-1990. WMO/OMM-No. 847.

Secretariat of the World Meteorological Organization, Geneva 
Tables

3 Table 1. Names and codes of the LCZ types (source: Stewart \& Oke, 2012)

\begin{tabular}{lll}
\hline Built types & Land cover types & Variable land cover properties \\
\hline LCZ 1 - Compact high-rise & LCZ A - Dense trees & $\mathrm{b}$ - bare trees \\
LCZ 2 - Compact mid-rise & LCZ B - Scattered trees & $\mathrm{s}$ - snow cover \\
LCZ 3 - Compact low-rise & LCZ C - Bush, scrub & $\mathrm{d}$ - dry ground \\
LCZ 4 - Open high-rise & LCZ D - Low plants & w - wet ground \\
LCZ 5 - Open mid-rise & LCZ E - Bare rock / paved & \\
LCZ 6 - Open low-rise & LCZ F - Bare soil / sand & \\
LCZ 7 - Lightweight low-rise & LCZ G - Water & \\
LCZ 8 - Large low-rise & & \\
LCZ 9 - Sparsely built & & \\
LCZ 10 - Heavy industry & & \\
\hline
\end{tabular}

Table 2. Zone properties of the LCZ system (source: Stewart \& Oke 2012)

\begin{tabular}{lcc}
\hline & \multicolumn{2}{c}{ Type of properties } \\
\cline { 2 - 3 } Properties & Geometric, surface cover & Thermal, radiative, metabolic \\
& sky view factor & surface admittance $\left(\mathrm{Jm}^{-2} \mathrm{~s}^{-1 / 2} \mathrm{~K}^{-1}\right)$ \\
& surface albedo ratio & anthropogenic heat output $\left(\mathrm{Wm}^{-2}\right)$ \\
& building surface fraction $(\%)$ & \\
impervious surface fraction $(\%)$ & \\
pervious surface fraction $(\%)$ & \\
height of roughness elements $(\mathrm{m})$ & \\
terrain roughness class &
\end{tabular}

8

9

10

11

12

13

14

15

\begin{tabular}{l|l}
\hline Range of absolute error $\left({ }^{\circ} \mathrm{C}\right)$ & Relative frequency \\
\hline $0.0-0.5$ & $78 \%$ \\
$0.5-1.0$ & $17 \%$ \\
$1.0-1.5$ & $4 \%$ \\
$1.5-2.0$ & $1 \%$ \\
$2.0-$ & $0 \%$ \\
\hline
\end{tabular}

Table 3. Pairs of similar built LCZ categories

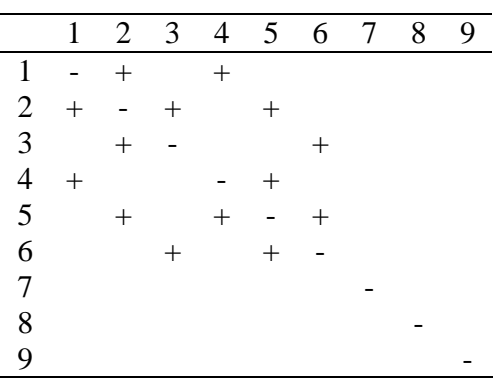


Figures

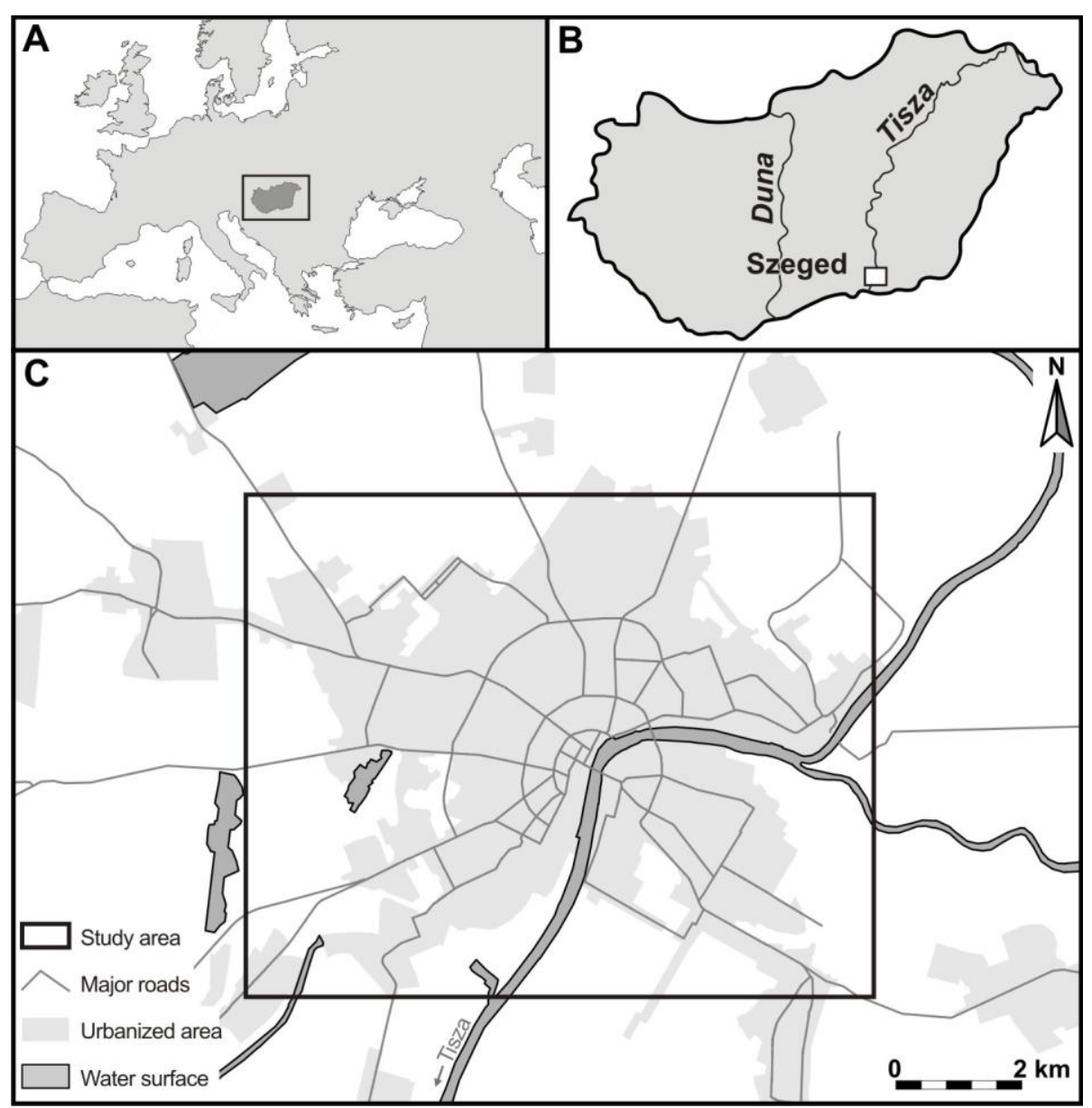

10 Fig. 1. (a) Location of the Szeged in Europe and (b) in Hungary, as well as (c) the study area in and around Szeged

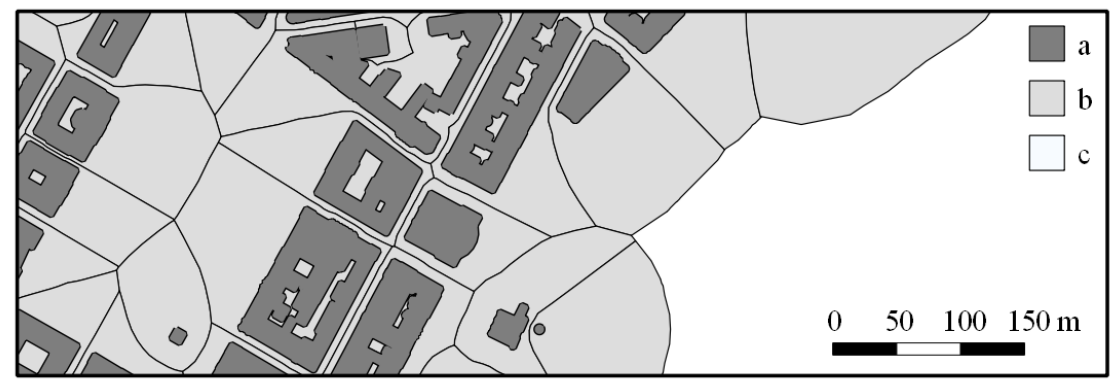

Fig. 2. Examples of lot area polygons in the study area (a: building block, b: lot area polygon, and c: open areas without buildings) 


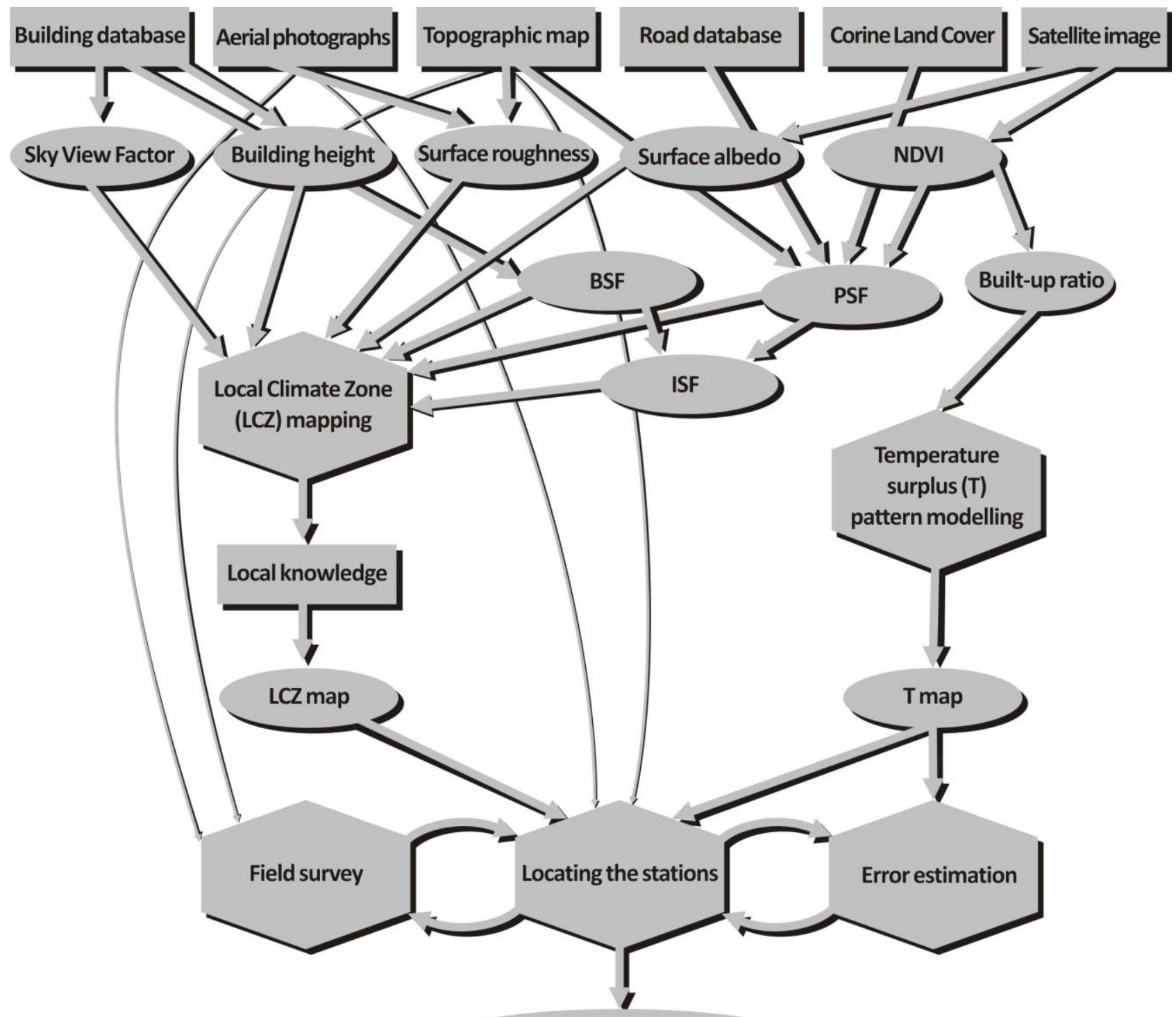

\section{Final location of stations}

Fig. 3. Flow chart of the selection of the representative sites of the temperature monitoring network stations in Szeged

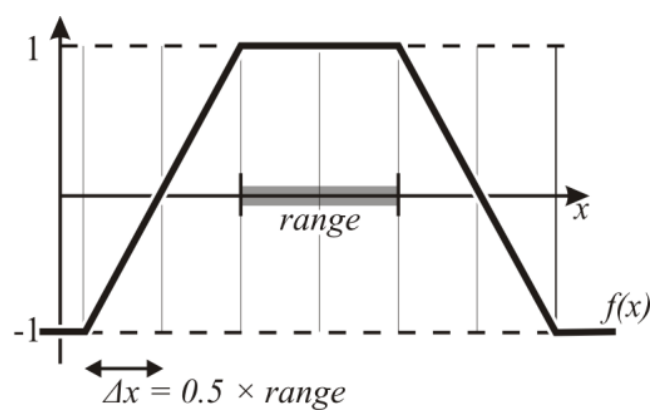


1 Fig. 4. Function of score assignment to a polygon according to its surface parameters. 2 Value $x$ is the calculated parameter (e.g. SVF) of the polygon, the range is the typical value for it in 3 a given LCZ category, $f(x)$ is the score function of this polygon-parameter-LCZ combination.
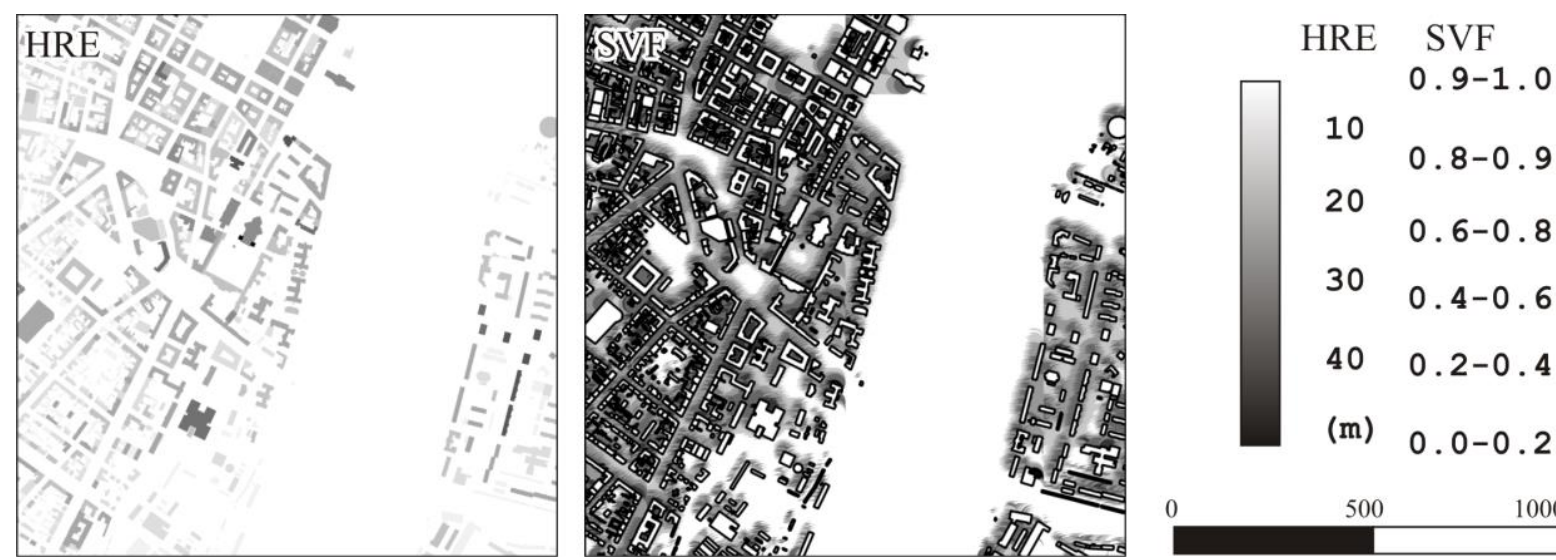

Fig. 5. Patterns of building height and sky view factor in a selected part of the study area as examples

10

11

12

13

14

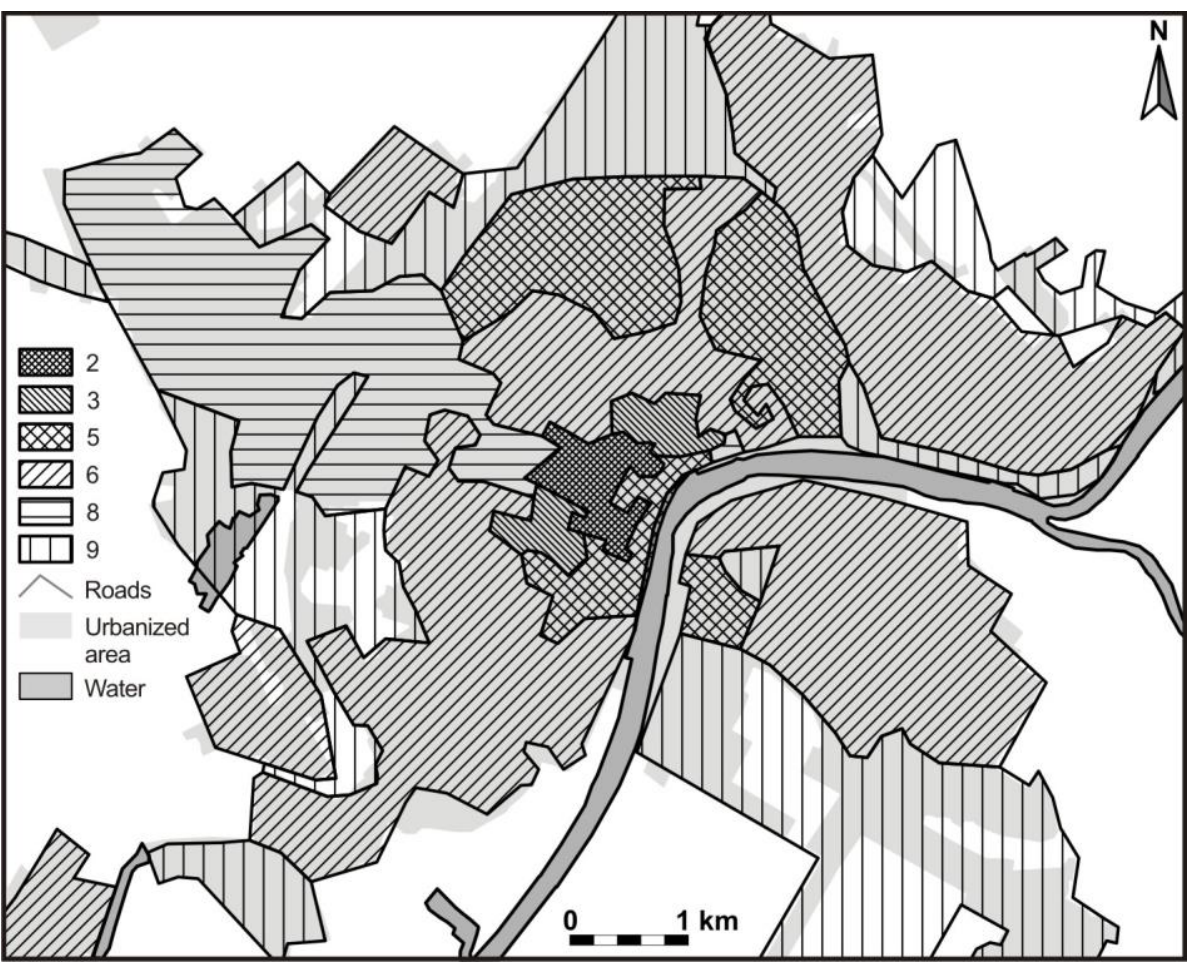

Fig. 6. The obtained LCZ map in Szeged (LCZ 2 - compact mid-rise, LCZ 3 - compact low-rise, LCZ 5 - open mid-rise, LCZ 6 - open low-rise, LCZ 8 - large low-rise and LCZ 9 - sparsely built) 


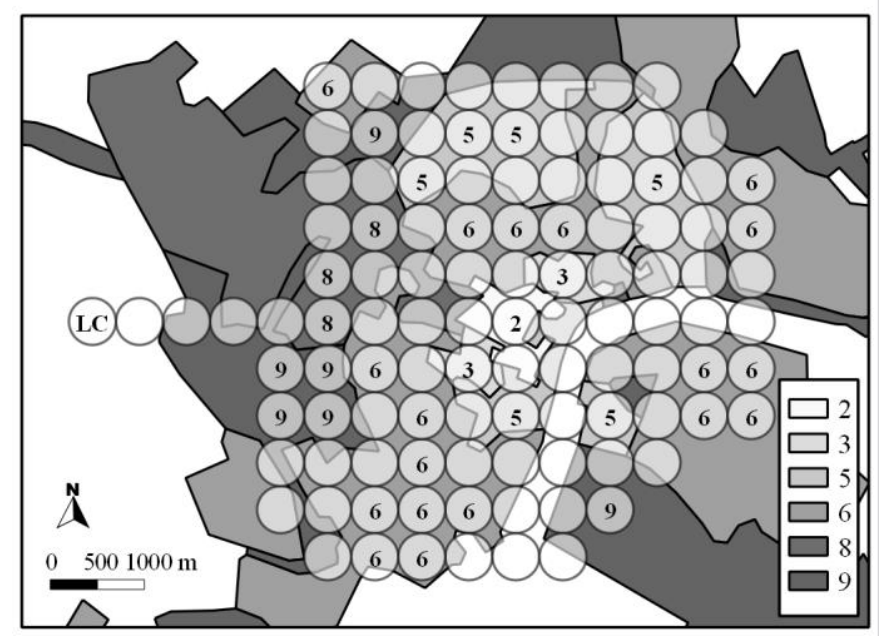

2 Fig. 7. Grid points of mobile measurements and their $250 \mathrm{~m}$ radius surroundings on the LCZ map of Szeged. Selected ones are marked with their type (LCZ 2 - compact mid-rise, LCZ 3 - compact low-rise, LCZ 5 - open mid-rise, LCZ 6 - open low-rise, LCZ 8 - large low-rise and LCZ 9 sparsely built, LC - land cover type, rural)

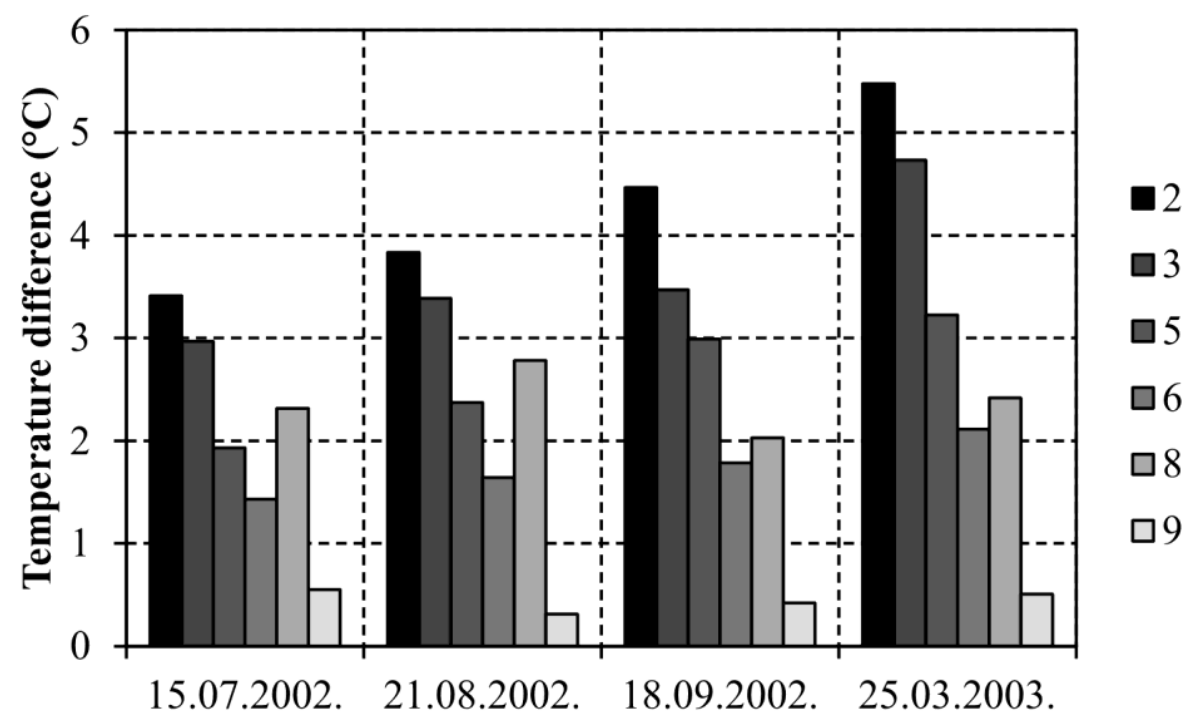

Fig 8. Average temperature differences between the selected circle areas and the furthermost one from the city (LCZ 2 - compact mid-rise, LCZ 3 - compact low-rise, LCZ 5 - open mid-rise, LCZ 6 - open low-rise, LCZ 8 - large low-rise and LCZ 9 - sparsely built) 


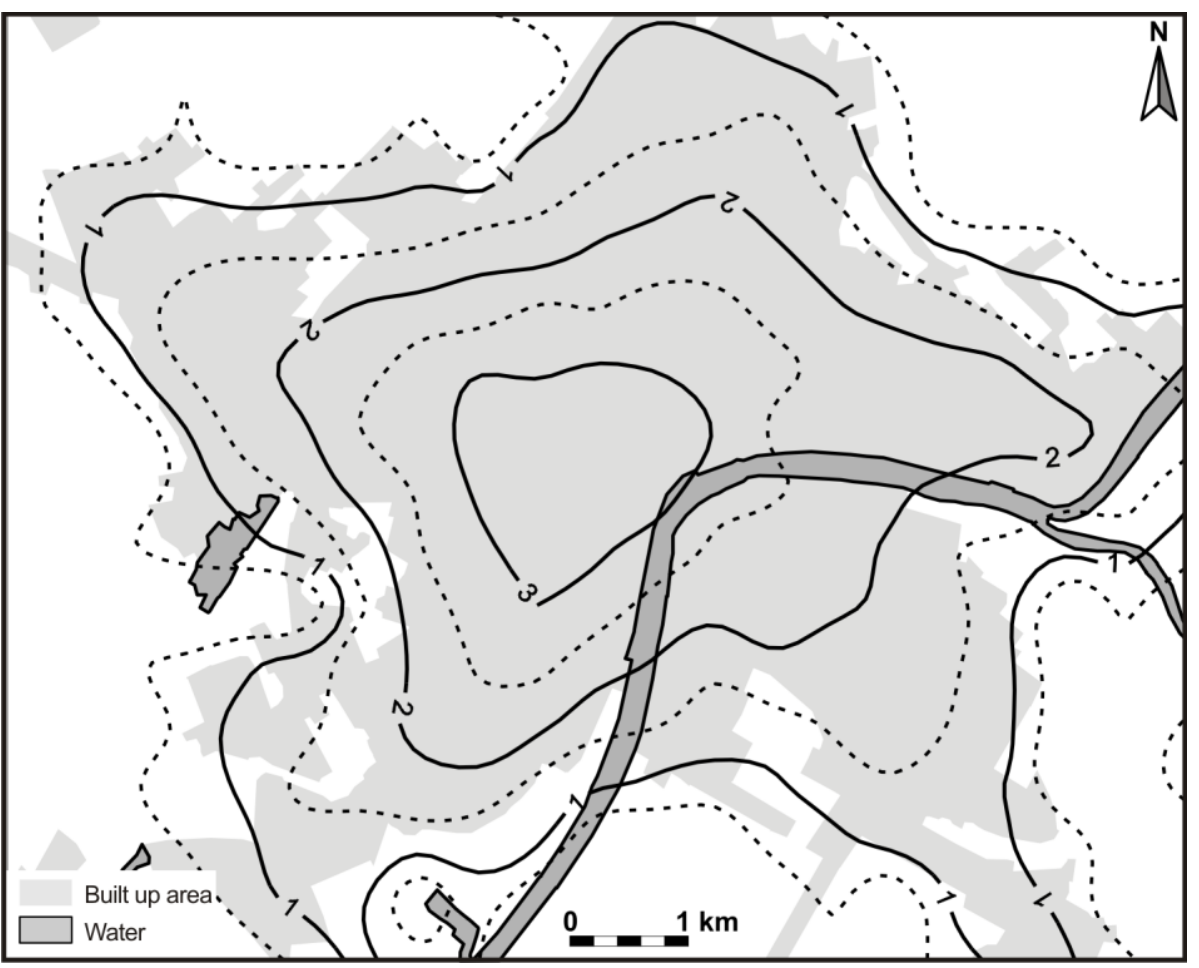

Fig. 9. Modelled temperature surplus pattern in Szeged [modified]

3

4

5

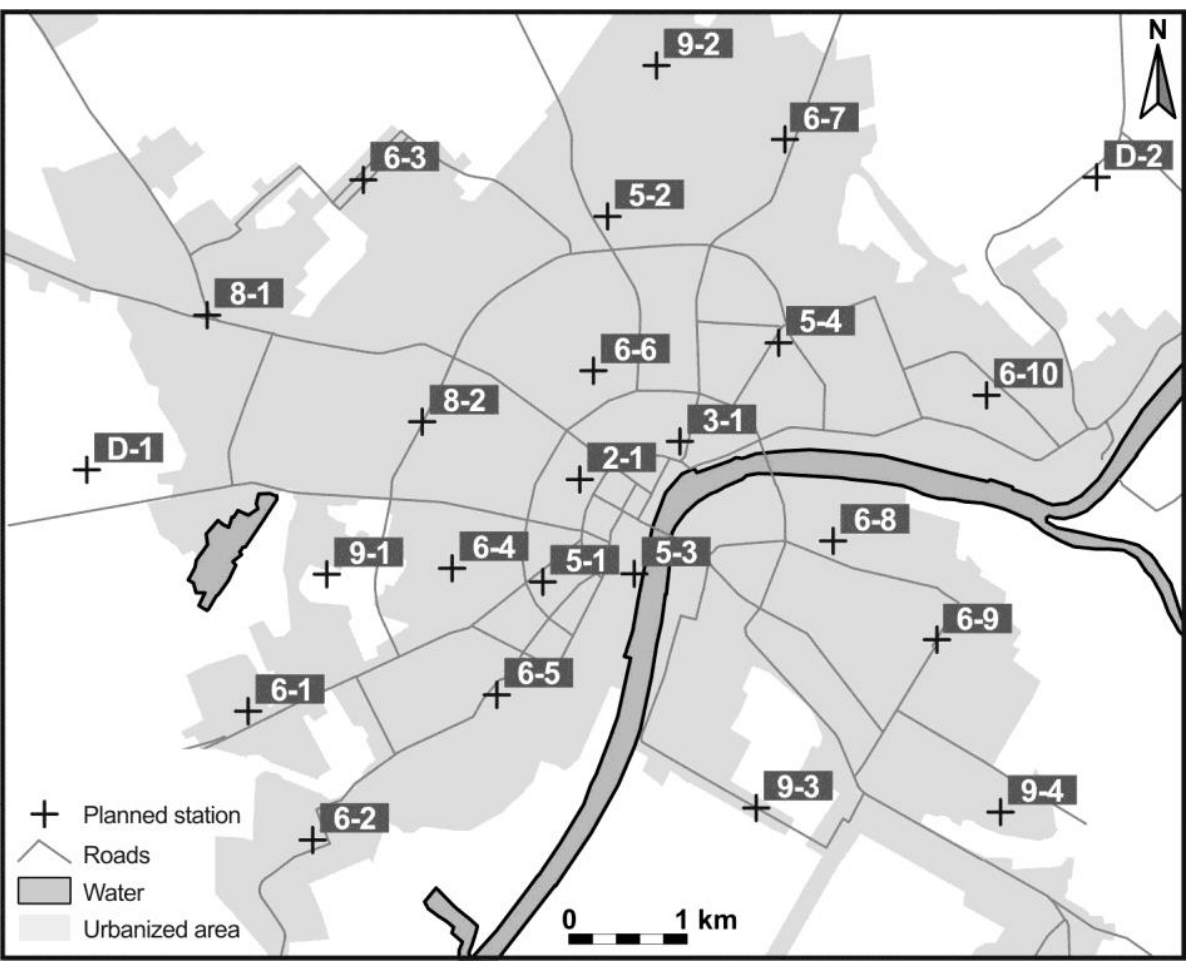

Fig. 10. Station locations of the urban monitoring network in Szeged with their notations (first number indicates the LCZ type, second one indicates the station number in a given LCZ type) 

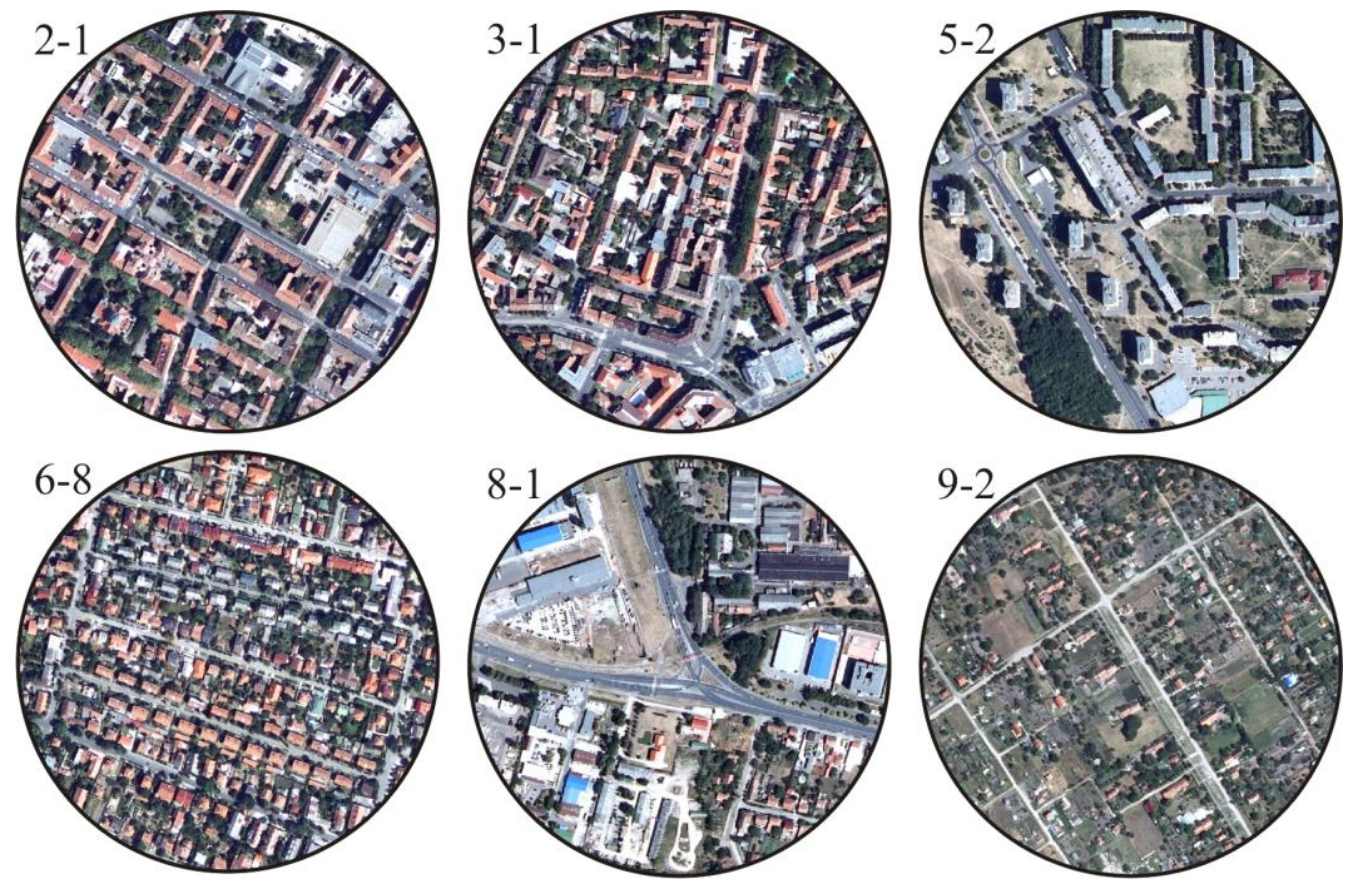

Fig. 11. Aerial photographs of the $250 \mathrm{~m}$ radius surroundings of six stations representing the six built LCZ types occurring in Szeged (LCZ 2 - compact mid-rise, LCZ 3 - compact low-rise, LCZ 5 - open mid-rise, LCZ 6 - open low-rise, LCZ 8 - large low-rise, LCZ 9 - sparsely built)

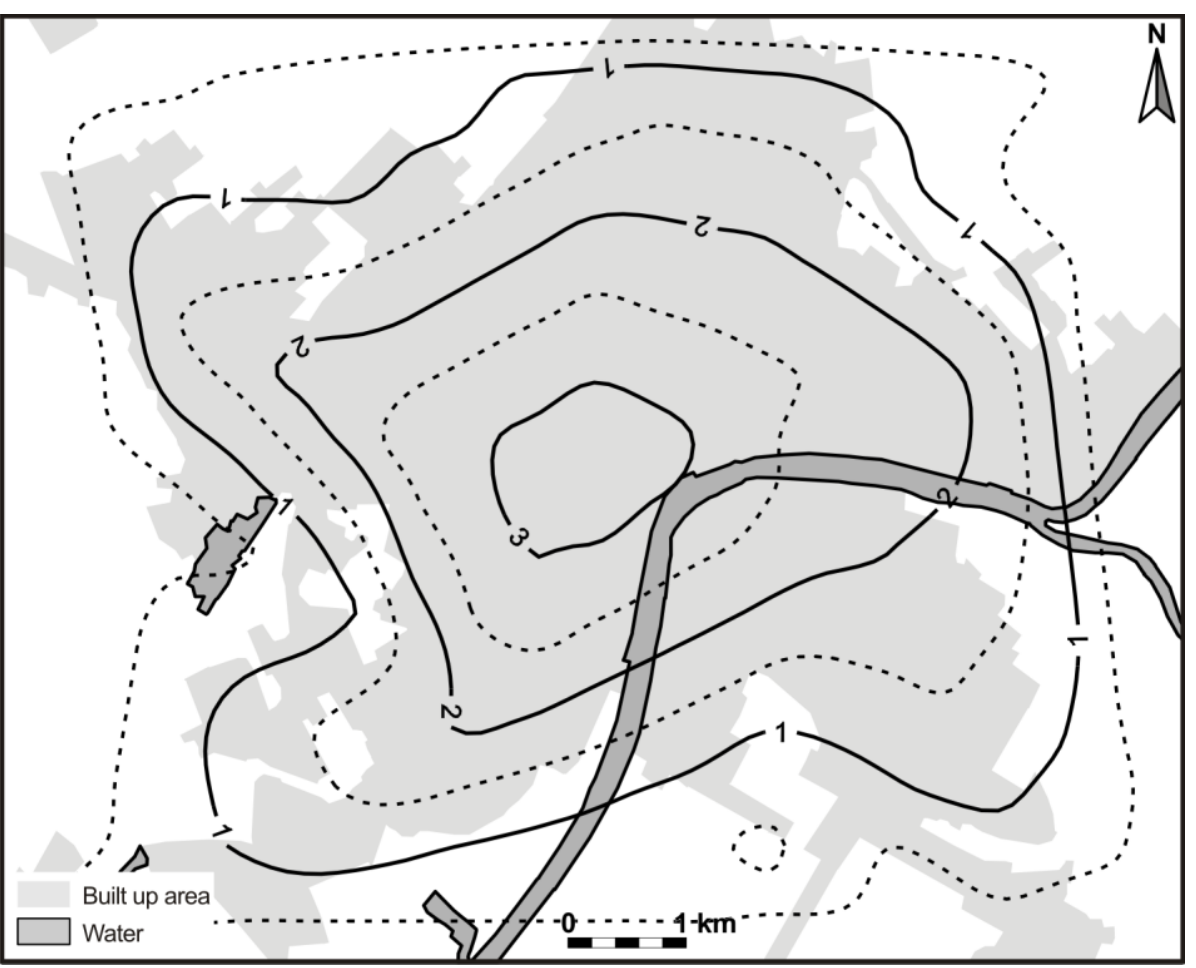

Fig. 12. Temperature surplus pattern $\left({ }^{\circ} \mathrm{C}\right)$ interpolated from the modelled values of the selected 24 station sites in Szeged [modified] 


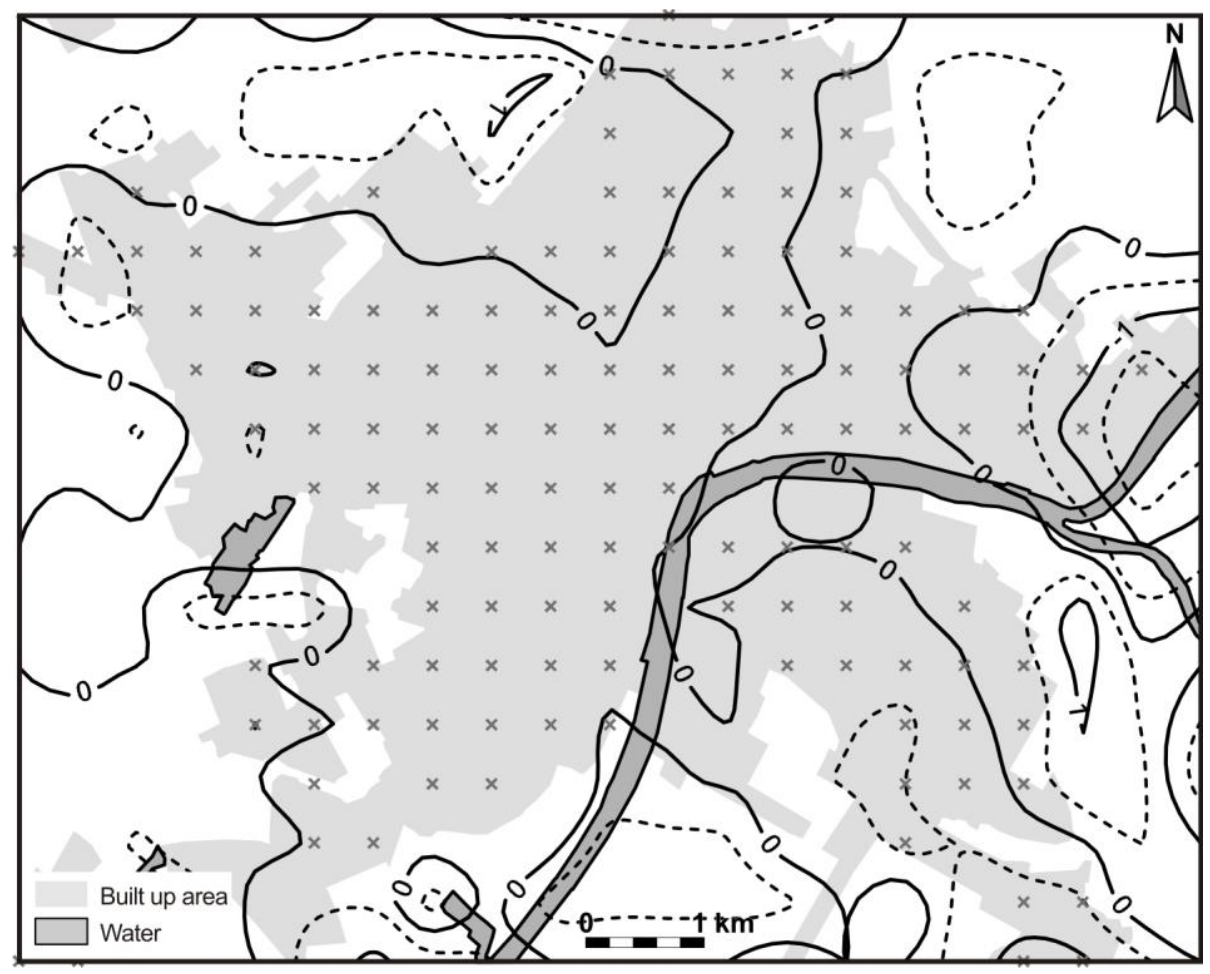

Fig. 13. Difference pattern $\left({ }^{\circ} \mathrm{C}\right)$ between the modelled and interpolated temperature patterns in Szeged. Grid points used in RMSE calculation are marked with " $\times$ ”. [modified]
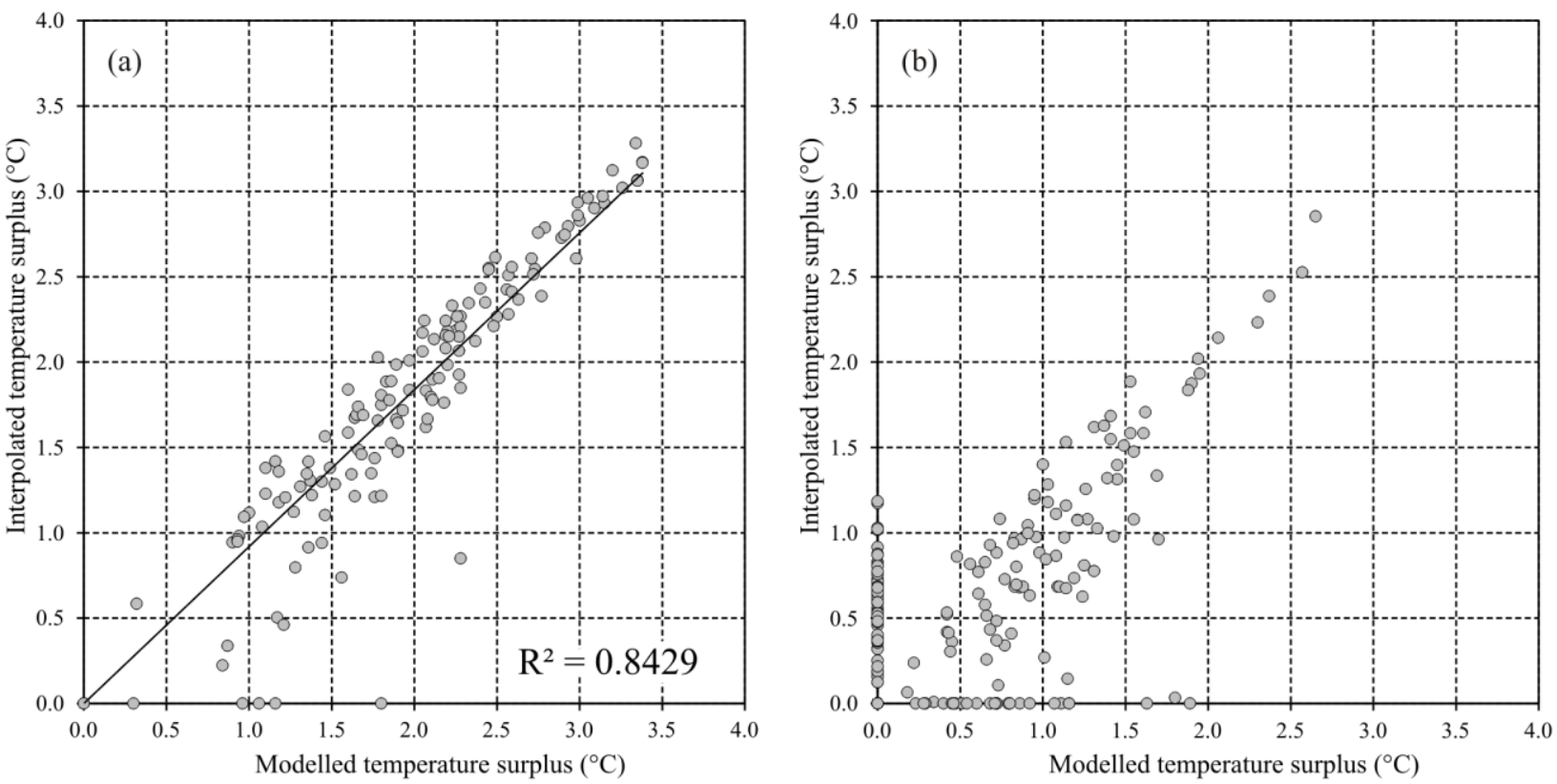

Fig. 14. Scatter-plot of the modelled and the interpolated temperature surplus of grid points on (a) built-up area, marked on Fig. 13 with “ $\times$ ”, (b) not built-up area. [new] 